\title{
Palinologia holocênica do testemunho Bom Jesus, margem leste da ilha do Marajó, Pará, Amazônia
}

\author{
Lívia Cardoso da Silva RODRIGUES ${ }^{1}$, Cristina do Socorro Fernandes de SENNA ${ }^{2}$
}

\begin{abstract}
RESUMO
A porção superior $(1,25 \mathrm{~m})$ do testemunho de sondagem Bom Jesus (TBJ), coletado no limite campo-mangue da Fazenda Bom Jesus, município de Soure, ilha do Marajó, Pará, Brasil, foi estudada através de análise palinológica de alta resoluçáo objetivando a determinaçáo da composição, abundância e diversidade de tipos polínicos bioindicadores de modificaçôes na paleovegetação durante o Holoceno. 16 amostras sedimentares de $2 \mathrm{~cm}^{3}$ foram tratadas de acordo com metodologia padrão em palinologia. Os programas Tilia e Tilia Graph foram utilizados para a construçáo dos diagramas palinológicos de abundância e concentração. A base do testemunho foi datada por ${ }^{14} \mathrm{C}$ em $2730 \pm 40$ anos A.P. Foram definidas três zonas palinológicas. A presença de pólen de Rhizophora com abundância máxima de $88 \%$ apontou dominância de mangue ao longo de todo o testemunho sedimentar. Variaçóes recorrentes na hidrodinâmica da baía do Marajó, caracterizadas por pulsos erosivos de curto período, parecem ter provocado redução na dominância de mangue. O incremento na abundância de tipos polínicos bioindicadores de campo inundável associados a elementos de restinga e floresta, evidenciam a migraçáo do campo inundável sobre o manguezal. Os dados indicam correlação com outros registros polínicos holocênicos de transgressão marinha para a costa norte amazônica no Holoceno Superior.
\end{abstract}

PALAVRAS-CHAVE: palinologia, manguezal; planície costeira, Holoceno, Amazônia.

\section{Palynological study of Holocene sediments of Bom Jesus core, east margin of the Marajó Island, Pará, Amazonia}

\begin{abstract}
The upper portion $(1.25 \mathrm{~m}$ ) of the sediment core Bom Jesus (TBJ), was collected in the field-mangrove limit of Bom Jesus Farm, municipality of Soure, island of Marajó, Pará, Brazil, was studied through pollen analysis high resolution aimed at determining the composition, abundance and diversity of the pollen types bioindicators of changes in the palaeobotany. 16 samples of sedimentary $2 \mathrm{~cm}^{3}$ were treated according to standard methodology. Tilia and Tilia Graph software were used for to construct abundance and concentration palinological diagrams. The core base was dated by ${ }^{14} \mathrm{C}$ in $2730 \pm 40$ years AP. Three palynological zones were identified. The mangrove ecosystem was dominant all sedimentary sequence of the TBJ core and was represented mainly for Rhizophora pollen type, which reaches $88 \%$ of the maximum relative abundance. Variations applicant hydrodynamics in the Marajó bay, characterized by short pulses of erosive period, seem to have caused reduction in the dominance of mangroves. The increase in the abundance of types growth bioindicators of field associated with elements of swamp forest and restinga, indicate the migration of the field on the mangrove swamp. The data show correlation with other palynological records of Holocene marine transgression to the north coast in the Upper Amazon Holocene.
\end{abstract}

KEYWORDS: palynology, mangrove, coastal plain, Holocene, Amazon.

1 Museu Paraense Emílio Goeldi.E-mail: licrodrigues@yahoo.com.br

${ }^{2}$ Museu Paraense Emílio Goeldi.E-mail: csenna@museu-goeldi.br 


\section{INTRODUÇÃO}

A palinologia tem sido utilizada em ambientes de sedimentação da planície costeira equatorial norte da América do Sul para a reconstruçáo de paleoambientes e entendimento das variaçôes do nível do mar durante o Holoceno. Esta porção da costa norte amazônica, compreende desde a Venezuela até o Estado do Maranhão no Brasil, e apresenta o mangue como principal ecossistema, formando um cinturão contínuo do Maranhão até o Amapá na fronteira com a Guiana Francesa (Rodrigues \& Senna, 2005).

A partir das pesquisas palinológicas iniciadas na Venezuela (Müller, 1959; Rull et al., 1989), Guiana (Van der Hammen, 1963), Suriname (Roeleveld, 1969; Laeyendecker-Roosenburg, 1966) e Guiana Francesa (Tissot \& Marius, 1992) foram identificados três eventos climáticos no limite Pleistoceno/ Holoceno pós-glacial e no Holoceno: o primeiro de transgressão marinha no Holoceno inferior (10.000-7.000 anos A.P. $\left.{ }^{1}\right)$ foi caracterizado pelo desenvolvimento de bosques de mangue, com dominância do gênero Rhyzophora; o segundo foi evidenciado por uma regressão marinha no Holoceno médio (a partir de 5.000 anos A.P) com a substituição de mangues por pântanos de água doce ou igapós e com dominância dos gêneros Symphonia, Ilex e Mauritia; o último episódio caracterizou-se por nova transgressão marinha no Holoceno tardio (a partir de 3.630 anos A.P.) evidenciado pela retomada dos ambientes de água doce por manguezais (Senna \& Absy, 2002).

No Brasil estes dados foram corroborados pelos registros polínicos da planície costeira dos Estados do Maranhão (Behling \& Costa, 1997) e Pará (Behling \& Costa, 2001; Behling et al., 2001; Behling, 2001; Senna, 2002; Senna \& Oliveira, 2002; Senna et al., 2005; Behling et al., 2004; Cohen et al., 2005; Vedel et al., 2005) (Tabela.1).

A ilha do Marajó situa-se no setor insular estuarino da zona costeira paraense, ${ }^{1}$ localizada entre a foz dos rios Amazonas e Gurupi (Alves et al., 2005). A margem leste da ilha apresenta planície costeira constituída por sedimentos holocênicos de

Tabela 1- Resumo de pesquisas palinológicas realizadas na costa norte amazônica. Summary of palinological research of north coastal amazonica.

\begin{tabular}{|c|c|c|c|c|c|c|}
\hline Evento Marinho & Datação (Anos A.P.) & Local & Ambiente & Tipo polínico & \multicolumn{2}{|c|}{ Palinomorfos } \\
\hline \multirow{9}{*}{ Transgressão } & Últimas décadas & Taperebal & Mangue & Rhizophora & & \multirow{4}{*}{ Rhizophora } \\
\hline & $650-530$ & Pesqueiro & Mangue & Rhizophora & & \\
\hline & A partir de 1000 & Península de Bragança & Mangue & Rhizophora & & \\
\hline & 2.170 - Atual & Bragança & & & & \\
\hline & 2.350 - Atual & Lago da Aranha & Mangue & Avicennia & & \multirow{4}{*}{ Avicennia } \\
\hline & $2.750-740$ & Barra Velha & Mangue & Rhizophora & & \\
\hline & 3.130 - Atual & Lago Curuçá & Mangue & Rhizophora & & \\
\hline & 3.630 - Atual & Crispim & Mangue & Rhizophora & & \\
\hline & A partir de 2.000 & & & & & \\
\hline \multirow{5}{*}{ Regressão } & $4.943-2.350$ & Lago da Aranha & $\begin{array}{l}\text { Pântano, água } \\
\text { doce }\end{array}$ & Mauritia, Symphonia & & Mauritia \\
\hline & $5.600-3.100$ & Lago Curuçá & & Mauritia & & \\
\hline & $5.950-5.750$ & Taperebal & & & & \multirow{3}{*}{ Symphonia } \\
\hline & $6.620-3.630$ & Crispim & Pântano, água doce & Mauritia & & \\
\hline & A partir de 5.000 & Guiana Francesa & Savana inundável & $\begin{array}{c}\text { Cyperaceae, Grami- } \\
\text { neae }\end{array}$ & & \\
\hline \multirow{10}{*}{ Transgressão } & Anterior a 6.500 & Taperebal & Mangue & Avicennia, Rhizophora & & \multirow{5}{*}{ Cyperaceae } \\
\hline & $6.850-4.943$ & Lago da Aranha & Mangue & Rhizophora & & \\
\hline & $7.250-5.600$ & Lago Curuçá & Mangue & Rhizophora & & \\
\hline & 7.000 & Playa Medina, Venezuela & Mangue & Rhizophora & & \\
\hline & $7.450-6.700$ & Lago Aquiri, Maranhão & Mangue & & & \\
\hline & $7.640-6.620$ & Crispim & & & & \multirow{5}{*}{ Gramineae } \\
\hline & $7.000-5.000$ & & & & & \\
\hline & 8.600 & Guiana & Mangue & Avicennia, Rhizophora & & \\
\hline & $9.000-5.000$ & Guiana Francesa & Mangue & Rhizophora & & \\
\hline & A partir de 10.000 & Suriname & Mangue & Rhizophora & 1 & \\
\hline
\end{tabular}

Correlação entre variações do nível do mar, tipos polínicos dominantes e registro fotográfico de palinomorfos. Correlation between changes sea level, dominant pollen types and microphotograph of palinomorphs.

1 Anos A.P.: Tradução do termo B.P. (before present), que significa "Antes do Presente", isto é, antes do ano de 1950 
origem flúvio-marinha, cuja porção interna (supramaré) é caracterizada por campos inundáveis, atingidos pela ação das marés durante o período chuvoso e nas marés de sizígia (França, 2003). A porção de intermaré é caracterizada por manguezais associados a restingas e várzeas de maré.

Segundo França e Souza Filho (2003) o registro dos movimentos da linha de costa da margem leste da ilha indica processos erosivos e mudanças no limite interno dos manguezais do município de Soure, no contato com os campos inundáveis e com o planalto costeiro. A sensibilidade deste ecossistema costeiro, diante de mudanças ambientais, associadas à dinâmica de sedimentaçẫo de curta duraçấo, ou a eventos climáticos ou tectônicos de maior duração, demanda pesquisas que contribuam para a conservação deste ambiente, considerando sua importância ecológica e sócio-econômica para as populaçóes locais e a ampla exploração desta área pelo turismo.

Esta pesquisa objetivou a interpretaçáa paleoecológica de tipos polínicos bioindicadores de paleoambientes holocênicos encontrados no testemunho sedimentar Bom Jesus e a correlação destes resultados com os dados relacionados para a costa norte amazônica.

\section{MATERIAL E MÉTODOS}

Área de estudo - Localiza-se no município de Soure, margem leste da Ilha de Marajó, Estado do Pará, Brasil, nas coordenadas geográficas $\left(0^{\circ} 43^{\prime} 40^{\prime \prime} \mathrm{S}\right.$ e $\left.48^{\circ} 31^{\prime} 02^{\prime \prime} \mathrm{W}\right)$ (Figura 1). O clima é tropical úmido com temperatura média anual de $27,3^{\circ}$ e sazonalidade definida entre período chuvoso, de dezembro a maio, e período seco, de junho a novembro. A região é dominada por regime de meso a macromarés (França, Souza Filho \& El-Robrini, 2007).

A influência flúvio-marinha compõe diferentes formações vegetais como os campos inundáveis com Gramineae, Leguminosae e Cyperaceae (IDESP, 1974; Amaral et al., 2007); manguezal, definido principalmente pela presença

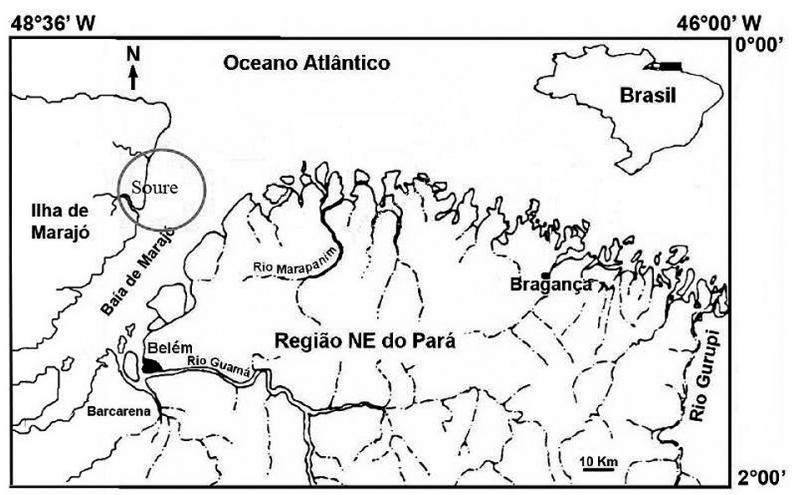

Figura 1 - Localização da área de estudo, planície costeira do município de Soure, ilha do Marajó, PA. (Adaptado de ALVES et al., 2005). de Rhizophora racemosa G.F.W.Mayer, Rhizophora mangle L., Avicennia germinans L., Laguncularia racemosa Gaertn. e Acrostichum aureum L. (França, Souza Filho \& El-Robrini, 2007); restingas (Santos \& Rosário, 1988; Bastos et al., 2003; Costa Neto et al., 1996); várzeas de maré e florestas de terra firme (IDESP, 1974; Amaral et al., 2007).

Sondagem - O testemunho sedimentar Bom Jesus (TBJ) de $4,2 \mathrm{~m}$ foi coletado através de vibra core (Mendes, 1994) a $4 \mathrm{~km}$ da linha de costa atual, no contato campo-mangue da porçáo de supramaré da planície costeira do município de Soure; dentro dos limites da Fazenda Bom Jesus, na coordenada geográfica 00³9'32”S - 48³1'8,67”W (França, 2003).

Para a análise palinológica foi utilizada apenas a porção superior do testemunho, $1,25 \mathrm{~m}$ dividido em 16 amostras sedimentares de $2 \mathrm{~cm}^{3}$ coletadas a cada $5 \mathrm{~cm}$ ou de acordo com mudanças na sedimentaçăo. Amostras compreendendo o intervalo $0-14 \mathrm{~cm}$ não foram coletadas, devido à contaminação por aterro utilizado na estrada que liga a Fazenda Bom Jesus a uma comunidade de pescadores.

O tratamento físico-químico das amostras seguiu metodologia padrão em análise palinológica (Erdtman, 1952, 1960; Feagri \& Iversen, 1950). Para o cálculo da concentraçáo (grãos $/ \mathrm{cm}^{3}$ ) foi adicionado o marcador palinológico Kochia scoparia (L.) Schrad. (Salgado-Labouriau \& Rull, 1986). Foram montadas três lâminas permanentes em gelatina glicerinada para cada nível sedimentar. Para a identificação de palinomorfos foi utilizada a coleçáo de referência do Laboratório de Palinologia e Paleoecologia da Amazônia do Museu Paraense Emílio Goeldi - LAPPAM, além de artigos de palinotaxonomia, paleopalinologia e melissopalinologia.

Em cada amostra, foram contados 300 grãos de pólen a partir de curvas de saturação (Rull, 1987). Os taxa identificados foram agrupados nas categorias de mangue, campo inundável, mata de restinga, floresta e várzea. Os palinomorfos das demais categorias como pólen exótico, microforaminíferos, algas, fungos, pólen não identificado e briófitas/pteridófitas foram contados separadamente e excluídos da soma polínica. Os programas Tília e Tília Graph (Grimm, 1987) foram utilizados para construção dos diagramas palinológicos de abundância relativa e concentração.

Para datação por ${ }^{14} \mathrm{C}$ uma amostra sedimentar do intervalo $(117-121 \mathrm{~cm})$ foi enviada para o Laboratório Beta Analytic Inc. Florida, U.S.A. A taxa de sedimentação foi calculada a partir da datação ${ }^{14} \mathrm{C}$, possibilitando a datação das demais zonas palinológicas por extrapolação.

\section{RESULTADOS}

O testemunho TBJ é constituído da base até $80 \mathrm{~cm}$ por sedimento lamoso. Entre $(80-40 \mathrm{~cm})$ o sedimento é lamoso com lâminas de areia. $(40-25 \mathrm{~cm})$ corresponde à lama cinza a 
negra com grânulos e seixos de laterita. $(25-0 \mathrm{~cm})$ corresponde a sedimento areno-argiloso com grânulos e seixos de laterita típicos da Formação Barreiras.

Foram registrados 82 tipos polínicos, restando 16 tipos ainda não identificados, 10 tipos de briófita/pteridófita além de algas e microforaminíferos. São apresentados os agentes de polinização, segundo Hoffmann (2002), para alguns táxons identificados, visando o melhor entendimento na relaçáo entre o agente de polinização e a concentração polínica
(Tabela 2). Três zonas palinológicas foram definidas. A base do testemunho sedimentar foi datada em $2.730 \pm 40$ anos A.P. (Beta 232412), indicando que a porçấo do testemunho TBJ analisada foi depositada durante o Holoceno Superior.

BJ-I $(123-89 \mathrm{~cm})$ : sedimento lamoso dominado por vegetação de mangue, (2730 \pm 40 anos A.P. - Beta 232412) evidenciada pela presença abundante de pólen de Rhizophora (79,33-69\%) (Figuras 2 e 3), (21000 a 42000 grãos de pólen/ $\mathrm{cm}^{3}$ ) (Figura 4), seguido de Avicennia em baixa porcentagem

Tabela 2- Lista dos táxons identificados nos sedimentos holocênios do testemunho TBJ, planície costeira de Soure, llha do Marajó/PA. Táxon list of TBJ core, coastal plane of Soure, Marajó island/PA.

\begin{tabular}{|c|c|c|c|c|}
\hline Família & Táxons & Hábito & Ambiente & Polinizador (Hoffmann, 2002) \\
\hline Alismataceae & Sagittaria & liana & campo inundável & \\
\hline Amaranthaceae & Alternanthera & erva & campo inundável & \\
\hline Amaranthaceae & Amaranthaceae & erva & campo inundável & \\
\hline Amaranthaceae & Chamissoa & erva & campo inundável & \\
\hline Anacardiaceae & Anacardiaceae & árvore & floresta & abelhas, mariposas, besouros \\
\hline Anacardiaceae & Anacardium & árvore & mata de restinga & \\
\hline Anacardiaceae & Tapirira & árvore & várzea & \\
\hline Annonaceae & Annona & árvore, arbusto & mata de restinga & besouros \\
\hline Apiaceae & Apiaceae & erva & mata de restinga & \\
\hline Apocynaceae & Apocynaceae & árvore, lianas & campo inundável & borboletas, abelhas \\
\hline Aquifoliaceae & Ilex & arbusto/árvore & várzea & inseto \\
\hline Araceae & Araceae & erva epífita & campo inundável & inseto \\
\hline Araliaceae & Didymopanax & arbusto/árvore & várzea & \\
\hline Arecaceae & Arecaceae & árvore & várzea & \\
\hline Arecaceae & Mauritia/ Mauritiella & árvore & floresta & abelhas, besouros \\
\hline Arecaceae & tipo 1 & árvore & várzea & \\
\hline Arecaceae & tipo 2 & árvore & várzea & \\
\hline Arecaceae & tipo 3 & árvore & várzea & \\
\hline Arecaceae & Euterpe oleracea Mart. & árvore & várzea & abelhas \\
\hline Arecaceae & Astrocaryum & árvore & várzea & \\
\hline Betulaceae & Alnus & árvore & pólen exótico & vento \\
\hline Bignoniaceae & Tabebuia & árvore & floresta & pássaros, morcegos, mariposas \\
\hline Bignoniaceae & Bigoniaceace & árvore & floresta & \\
\hline Bombacaceae & Paquira aquatica Aubl. & árvore & várzea & \\
\hline Bombacaceae & Bombax & árvore & várzea & \\
\hline Boraginaceae & Boraginaceae & árvore & & \\
\hline Burseraceae & Protium heptaphyllum (Aubl.) March. & árvore & várzea & \\
\hline Clusiaceae & Symphonia globulifera L. & árvore & várzea & pássaros \\
\hline Clusiaceae & Callophyllum & árvore & várzea & \\
\hline Compositae & Mikania & liana & campo inundável & \\
\hline Compositae & Vernonia & liana & campo inundável & \\
\hline Convolvulaceae & Merremia & liana & campo inundável & borboleta \\
\hline Cyperaceae & Cyperaceae tipo 1 & erva & campo inundável & vento \\
\hline Cyperaceae & Cyperaceae tipo 2 & erva & campo inundável & \\
\hline Dilleniaceae & Dilleniaceae & erva & mangue & \\
\hline Euphorbiaceae & Sapium & árvore & mata de restinga & \\
\hline Euphorbiaceae & Alchornea & árvore & floresta & \\
\hline Fabaceae & Centrosema & liana & mata de restinga & abelhas \\
\hline Fabaceae & Machaerium & árvore & & \\
\hline
\end{tabular}


Tabela 2- Continuação

\begin{tabular}{|c|c|c|c|c|}
\hline Família & Táxons & Hábito & Ambiente & Polinizador (Hoffmann, 2002) \\
\hline Flacourtiaceae & Casearia & árvore & mata de restinga & \\
\hline Gramineae & Gramineae & erva & campo inundável & vento \\
\hline Lamiaceae & Hyptis & erva & floresta & abelhas, pássaros \\
\hline Lauraceae & Ocotea & árvore & várzea & \\
\hline Caesalpiniaceae & Bauhinia pulchella Benth. & liana & floresta & pássaros \\
\hline Caesalpiniaceae & Bauhinia & liana, árvore & floresta & pássaros \\
\hline Caesalpiniaceae & Cassia & árvore, arbusto & floresta & pássaros \\
\hline Caesalpiniaceae & Schizolobium & árvore & floresta & pássaros \\
\hline Caesalpiniaceae & Crudia & árvore & & pássaros \\
\hline Caesalpiniaceae & Macrolobium & árvore & várzea & pássaros \\
\hline Caesalpiniaceae & Tachigalia & árvore & & pássaros \\
\hline Mimosaceae & Mimosaceae & árvore & floresta & \\
\hline Mimosaceae & Acacia & árvore, liana & mata de restinga & \\
\hline Mimosaceae & Anadenanthera & árvore & & \\
\hline Mimosaceae & Dinizia & árvore & floresta & \\
\hline Mimosaceae & Entada & liana & mata de restinga & \\
\hline Malpighiaceae & Byrsonima & árvore & mata de restinga & \\
\hline Malpighiaceae & Banisteriopsis & arbusto & mata de restinga & abelhas \\
\hline Malvaceae & Hibiscus & arbusto & mata de restinga & \\
\hline Meliaceae & Trichilia & árvore & várzea & \\
\hline Memecylaceae & Tibouchina & arbusto & campo inundável & \\
\hline Memecylaceae & tipo 1 & árvore & & \\
\hline Memecylaceae & tipo 2 & árvore & & \\
\hline Memecylaceae & tipo 3 & árvore & & \\
\hline Memecylaceae & Miconia & árvore & várzea & \\
\hline Moraceae & Cecropia & árvore & floresta & vento, inseto \\
\hline Myrtaceae & Myrtaceae & árvore, arbusto & campo inundável & insetos \\
\hline Ochnaceae & Ouratea & árvore, arbusto & mata de restinga & \\
\hline Onagraceae & Ludwigia & erva aquática & campo inundável & \\
\hline Polygalaceae & Polygalaceae & liana, erva, arbusto & mata de restinga & \\
\hline Protecaea & Roupala & árvore & floresta & \\
\hline Rhizophoraceae & Rhizophora mangle L. & árvore & mangue & Anemófila \\
\hline Rhizophoraceae & Rhizophora tipo 1 & árvore & mangue & Anemófila \\
\hline Rubiaceae & Psycotria & arbusto, erva & mata de restinga & insetos, aves, morcegos \\
\hline Rubiaceae & Borreria & erva & mata de restinga & \\
\hline Sapindaceae & Paullinea & liana & mata de restinga & insetos \\
\hline Sapindaceae & Cupania & árvore & mata de restinga & \\
\hline Solanaceae & Solanum & árvore, arbusto & floresta & \\
\hline Tiliaceae & Apeiba & árvore & várzea & \\
\hline Ulmaceae & Celtis & arbusto, liana & floresta & \\
\hline Ulmaceae & Trema & árvore & floresta & \\
\hline Verbenaceae & Avicennia germinas L. Stearn. & árvore & mangue & abelhas \\
\hline Pteridófita/Briófita & Esporo monolete & erva/liana & ampla distribuição & vento/água \\
\hline Pteridófita/Briófita & Esporo trilete liso & erva/liana & ampla distribuição & vento/água \\
\hline Pteridófita/Briófita & Esporo trilete rugoso & erva/liana & ampla distribuição & vento/água \\
\hline Pteridófita/Briófita & Polypodiaceae & erva/liana & ampla distribuição & vento/água \\
\hline Pteridófita/Briófita & Acrostichum aureum L. & erva/liana & ampla distribuição & vento/água \\
\hline Pteridófita/Briófita & Polypodium tipo & erva/liana & ampla distribuição & vento/água \\
\hline Pteridófita/Briófita & Polypodium rugoso & erva/liana & ampla distribuição & vento/água \\
\hline Pteridófita/Briófita & Selaginellaceae & erva/liana & ampla distribuição & vento/água \\
\hline Pteridófita/Briófita & Esporo c/ espinhos & erva/liana & ampla distribuição & vento/água \\
\hline
\end{tabular}


Tabela 2- Continuação

\begin{tabular}{|c|c|c|c|c|}
\hline Família & Táxons & Hábito & Ambiente & Polinizador (Hoffmann, 2002) \\
\hline Microforaminífero & Microforaminífero & & aquático marinho & \\
\hline Algas & Algas & & aquático marinho & \\
\hline
\end{tabular}

$(<2 \%)$. Outros táxons arbóreos, bioindicadores de várzea de maré como Arecaceae, Leguminosae (1\%), Mauritia, ocorrem associados a Gramineae e Cyperaceae (1\%), indicando a presença de campo inundável, ou área pantanosa próxima, entretanto, em baixas porcentagens, ou sem concentraçóes significativas. Provavelmente, a substituição desta vegetação pelo mangue se deu em virtude de transgressão marinha a partir de 5.000 anos A.P., registrada em vários pontos da costa norte amazônica (Behling, 2001; Behling et al., 2001; Senna, 2002). No entanto, entre $(99-89 \mathrm{~cm})$ ocorre retração do manguezal, com a redução na dominância de Rhizophora (72\%-69\%), em contraste com aumento da abundância de Cyperaceae (4,23\%) e Gramineae (9,15\%), de Avicennia (3\%) e Leguminosae (2\%), bem como, de esporos de Briófita/ Pteridófita (10\%). A ocorrência de um microforaminífero indica maior contribuição marinha neste período.

BJ-II (89-45 cm): sedimentos lamosos com níveis de areia (2002 anos A.P.) com dominância de pólen de Rhizophora (76\%-70,67\%) (Figuras 2 e 3). A abundância de Rhizophora atinge $88 \%$, com concentração um pouco maior que em BJ-I (23000-52000 grãos/ $\mathrm{cm}^{3}$ ) (Figura 4). Avicennia tipo mantém a mesma porcentagem e concentraçáo da zona subjacente. Gramineae e Cyperaceae (2\%) permanecem acompanhadas por baixas porcentagens de Arecaceae, Combretaceae/Melastomataceae, Leguminosae, Rubiaceae e Ulmaceae.

A diminuição da abundância do pólen de Rhizophora $(70,67 \%)$ entre $59-45 \mathrm{~cm}$ é acompanhada pelo aumento de Gramineae (4\%) e Cyperaceae (2\%), além da presença de outros grãos de pólen bioindicadores de ambiente úmido, a partir de $59 \mathrm{~cm}$, como Apocynaceae, Anacardiaceae, Araliaceae/ Euphorbiaceae, Bignoniaceae, Compositae, Fabaceae, Leguminosae, Solanaceae, Ocotea e Protium, também em baixas porcentagens $(<2 \%)$ e sem concentraçóes significativas. A presença de esporos de Pteridófitas manteve-se em torno de 5\%. A ocorrência de microforaminíferos foi registrada nos intervalos (84-82 $\mathrm{cm})$ e $(53-51 \mathrm{~cm})$, ratificando a indicação de conexão com a água do mar.

BJ-III (45-14 cm): sedimentação lamosa com presença de seixos de laterita (1012 anos A.P). A elevada abundância relativa de Rhizophora (83,33\%-67,33\%) (Figura 2) é acompanhada por uma diminuição da concentração (4300016000 grãos $/ \mathrm{cm}^{3}$ ) deste palinomorfo (Figura 4). Elementos de Avicennia mantém abundância e concentração das zonas subjacentes (1\%-3\%), acompanhados pela presença de Arecaceae, Bignoniaceae e Solanaceae (1\%). No intervalo (38$36 \mathrm{~cm}$ ) foi registrada a ocorrência de grão de pólen exótico do gênero Alnus, Betulaceae.

A partir de $23 \mathrm{~cm}$ a sedimentação passa a areno-argilosa com seixos de laterita, caracterizada por incremento na abundância de Gramineae (4\%-12\%). O decréscimo na porcentagem de Rhizophora $(67,33 \%)$ é acompanhado pelo incremento de Cyperaceae $(5 \%)$ e pela presença de Tibouchina e Macrolobium (1\%), típicos de ambientes de várzea. $\mathrm{O}$ aumento expressivo de esporos de briófita/

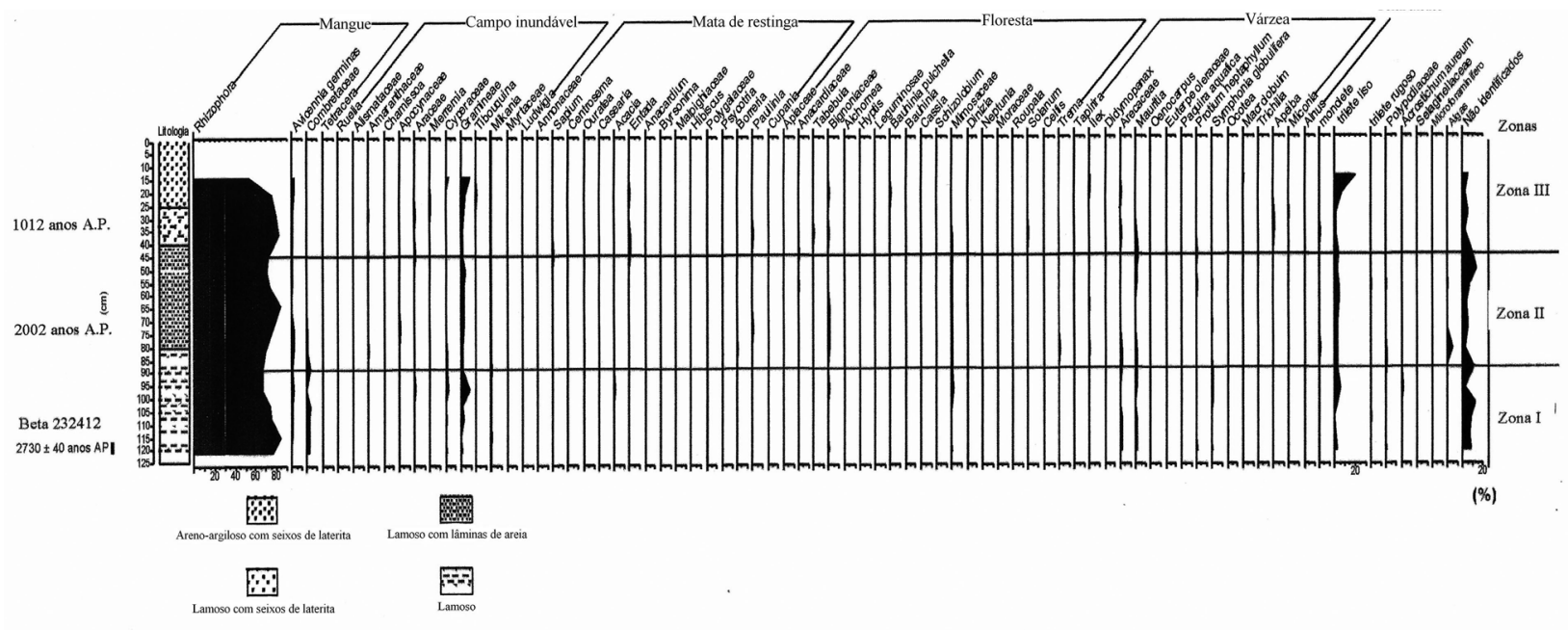

Fugra 2 - Diagrama palinológico de abundância relativa dos táxons encontrados no testemunho TBJ. 


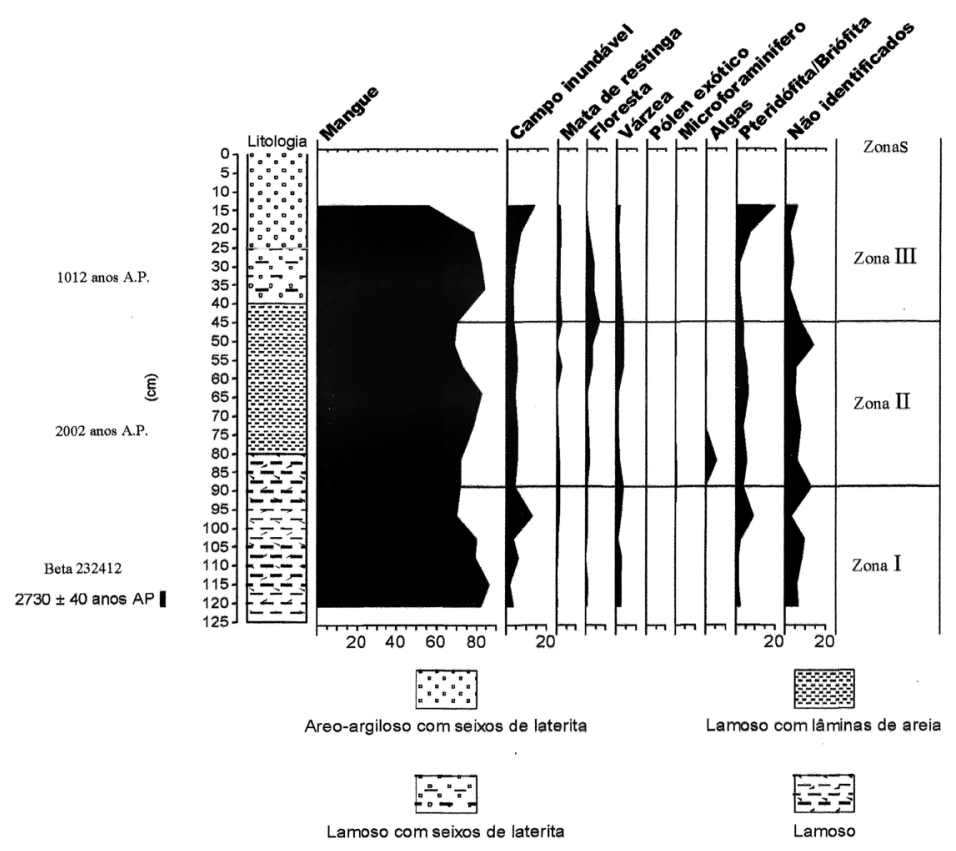

Figura 3 - Diagrama palinológico de abundância relativa por formação vegetal dos táxons encontrados no testemunho TBJ.

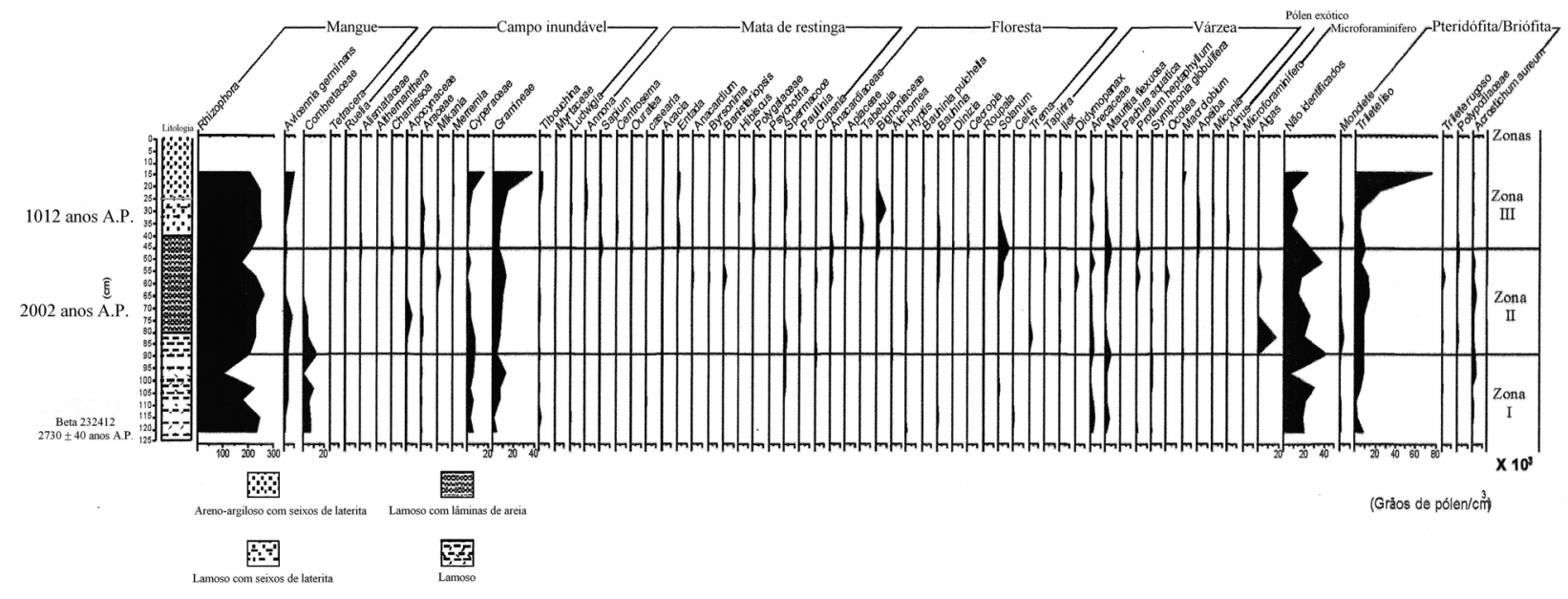

Figura 4 - Diagrama palinológico de concentração dos táxons encontrados no testemunho TBJ.

pteridófita $(2,33 \%-25,67 \%)$ reforça as condições úmidas do ambiente e a presença de outro microforaminífero no intervalo $(16-14 \mathrm{~cm})$ indica novamente, maior contribuição marinha neste período.

\section{DISCUSSÃO}

$\mathrm{O}$ aporte de palinomorfos foi considerado de origem flúvio-marinha, representado em sua maioria por pólen alóctone, o que segundo Müller (1959), demonstra forte relação com a composição local da vegetação. A ocorrência de pólen exótico de longa distância, Alnus, típico dos Andes, indica que este grão foi transportado até a área de estudo, possivelmente, a partir de maior descarga do Rio Amazonas, de acordo com Müller (1959), Behling et al. (2004) e Cohen et al. (2005).

A dominância de mangue ao longo de todo o testemunho sedimentar é representada pela elevada abundância do pólen de Rhizophora (Figura 2). Os valores de abundância maiores que $60 \%$, indicam não só a adaptação deste ecossistema a hidrodinâmica local, mas seu estabelecimento, provavelmente, em período mais antigo, durante o Máximo Transgressivo 
Holocênico a partir de 5.000 anos A.P. A dominância de Rhizophora é ainda ratificada por sua elevada produção polínica e dispersão anemófila, potencializada pela brisa marinha da zona costeira (Hofmann, 2002).

O último episódio registrado para a costa norte amazônica através de análise polínica é definido por nova transgressão marinha indicando a retomada dos espaços com composição florística característica de ambientes de água doce, por bosques de mangue, com dominância de Rhizophora no Marajó (2750 anos A. P), segundo Behling et al. (2004), e Avicennia, seguida de pólen de Rhizophora nas Guianas (Van der Hammen, 1963). Somente os dados palinológicos do lago Aquiri, no Maranhão, registram a presença contínua de manguezais durante todo o Holoceno, segundo Behling \& Costa (1997) (Tabela 1)

Os resultados encontrados a partir do testemunho Bom Jesus corroboram os dados palinológicos citados para a costa norte amazônica, entretanto, evidenciaram mudanças periódicas na composição da comunidade vegetal da margem leste da ilha do Marajó. Tal comportamento cíclico está caracterizado nas zonas palinológicas I e III, cujo aumento ou diminuição na dominância de mangue, representado pelo pólen de Rhizophora, é acompanhado por diminuição ou aumento da abundância de bioindicadores característicos de campo inundável, associados a elementos de várzea, restinga e floresta. Acréscimos maiores na abundância relativa de bioindicadores de floresta, várzea e restinga são registrados somente a partir da zona palinológica II, cuja porção sedimentar corresponde à deposição lamosa com lâminas de areia (Figura 3).

Na zona palinológica II, a diminuição da dominância de mangue indica que, nestes períodos, as condiçóes ambientais foram mais favoráveis a colonização por outros táxons como Gramineae e Cyperaceae, característicos de campo inundável, associados ainda a elementos de várzea como Macrolobium, Mauritia flexuosa Mart. e Protium heptaphyllum (Aubl.) March.

Os dados palinológicos do testemunho TBJ também correspondem a processos recorrentes, provavelmente relacionados a pulsos climáticos ou mudanças hidrodinâmicas na foz do rio Amazonas, incluindo a ilha do Marajó, citados por França e Souza Filho (2003). Segundo estes autores, eventos descontínuos de progradação da linha de costa da margem leste da ilha são interrompidos por pulsos erosivos de curto período e de intensidade moderada, causados por alteraçôes na hidrodinâmica local, com a deposição de cordóes arenosos praiais, sem, no entanto, promover uma substituição de ecossistemas durante o período avaliado, fato evidenciado através da analise palinológica em questão.

Deve-se considerar também, que o testemunho sedimentar TBJ foi coletado a $4 \mathrm{~km}$ da linha de costa atual, na porção interna da planície costeira, porção a qual, segundo França e Souza Filho (2003), apresenta as maiores taxas de erosão da porção leste da ilha do Marajó. Tal processo, identificado pelo soterramento de árvores adultas de mangue, com a formação de terraços lamosos, onde a vegetação de mangue náo consegue se fixar é caracterizado pela sedimentação arenosa, em condiçóes de maior energia. A recorrência na mudança de sedimentação é registrada sob a forma de cordóes arenosos, no interior do mangue, indicando antigas linhas de costa, colonizadas por vegetação adaptada à sedimentação arenosa, justificando a ocorrência de mata de restinga, intercalada com o mangue de supramaré.

Desta forma, os processos erosivos atuantes na linha de costa da planície costeira de Soure são registrados de maneira mais sutil na planície interna ou de supramaré. A descrição sedimentar realizada para a porção média do testemunho de sondagem TBJ aponta a ocorrência de sedimentação lamosa com níveis de areia, denominada "stripe lamination", por França (2003), corroborando a hipótese de formação de linhas de costa sucessivas, em processo progradacional, descontínuo. Assim, o processo erosivo, caracterizado por sedimentação arenosa sob condiçóes de maior energia, segundo França e Souza Filho (2003), durante os últimos 15 anos na planície costeira de Soure está correlacionado com a última fase transgressiva citada para a costa norte amazônica (Tabela 1).

Tal situação pode estar associada à alternância entre períodos úmidos e secos, influenciados provavelmente, pela variação climática, responsável também pelas prováveis mudanças na hidrodinâmica local. A ocorrência de microforaminíferos e outros elementos marinhos na planície costeira de supramaré, observado nas três zonas palinológicas (Figura 2) sugere maior influência da salinidade em períodos secos. Tal situação, decisiva para a permanência de algumas espécies vegetais de mangue, pode ser explicada pelo atual isolamento relativo da referida área, alimentada somente nas marés de sizígia, o que lhe confere a situação de manguezal de supramaré.

A datação ${ }^{14} \mathrm{C}$ da base do testemunho TBJ $(2730 \pm 40$ anos A.P. - Beta 232412) reforça a correspondência entre os eventos marinhos ocorridos na zona costeira paraense, principalmente, os registros de Behling et al. (2004) para Barra Velha, na ilha do Marajó, cuja datação radiocarbônica da base do testemunho de sondagem é de 2.750 anos AP. Contudo, Behling et al. (2004) afirmam que a subida do nível do mar registrada na península de Bragança (Cohen \& Lara, 2003) durante os últimos 30 anos, não é claramente definida no Marajó, devido à influência fluvial da área não ser diretamente submetida ao oceano. Ainda segundo estes autores, a vegetação de restinga seria menos freqüente em locais mais elevados da planície costeira dominada por manguezal. 
Entretanto, a presente análise palinológica indica a ocorrência de grãos de pólen bioindicadores de restinga associados aos tipos polínicos de mangue ao longo do Holoceno Superior, registrados a partir da formação de cordóes arenosos em períodos erosivos recorrentes para a planície costeira (França e Souza Filho, 2003). A análise indica que o evento de transgressão marinha caracterizado pela presença de mangue com dominância de Rhizophora, apresenta peculiaridades relativas à hidrodinâmica da baía do Marajó, evidenciadas pela diminuição da abundância relativa do mangue e do incremento na vegetação de campo inundável associado a outros ecossistemas.

Pode-se afirmar, portanto, que a partir da análise palinológica do testemunho TBJ, associada às dataçóes ${ }^{14} \mathrm{C}$ e à correlaçáo com outros registros polínicos holocênicos, realizados ao longo da costa norte amazônica, os eventos registrados para a planície costeira de supramaré do município de Soure, estáo inseridos em evento regional de transgressão marinha, registrado por toda a zona costeira paraense no Holoceno Superior.

\section{CONCLUSÕES}

O processo erosivo de retrogradaçáo atual da linha de costa, ao qual a margem leste da ilha do Marajó está submetida, é registrado de maneira mais sutil, na planície costeira interna e está relacionado provavelmente com a migração do campo sobre as áreas de mangue. Os tipos polínicos de mangue são dominados pela ocorrência de Rhizophora mangle L., registrada ao longo de todo o testemunho sedimentar. Entretanto, sua dominância ora sofre decréscimo, ora aumenta, concomitante ao incremento ou diminuiçáo da abundância de elementos de campo inundável e várzea, provavelmente influenciada por pulsos climáticos, de curta duração, definindo três zonas palinológicas, integradas a um evento transgressivo descontínuo, de maior duração.

Os eventos climáticos ocorridos no Holoceno Superior parecem ter atingido a margem leste da ilha do Marajó como um todo. Entretanto, para o restante da costa norte amazônica é necessário incrementar os estudos palinológicos, utilizando a análise palinológica de alta resolução, para interpretaçôes paleoecológicas mais detalhadas, considerando as características fisiográficas de cada região, separadamente.

\section{AGRADECIMENTOS}

A Dra. Carmena França (Universidade Federal do Pará - UFPA) por ceder o testemunho sedimentar para a análise palinológica. Ao Conselho Nacional de Desenvolvimento Científico e Tecnológico (CNPq), Coordenação de Botânica do Museu Goeldi, Coordenação de Ciências da Terra e Ecologia do Museu Goeldi.

\section{BIBLIOGRAFIA CITADA}

Absy, M.L, Absy \& Servant, M.1993. The history of climate and vegetation in pollen study. Ciência Hoje, 16 (93): 26-30 (in Portuguese).

Absy, M.L. 1975. Pollen and spores of the Quaternary of Santos, Brazil. Pólen e esporos do Quaternário de Santos, Brasil. Hoehnea, 5: 1-26 (in Portuguese).

Absy, M.L. \& Senna, C. 2003. The mangroves of the northern brasilian coast. Organizado por Marcus. E. B. Fernandes. Maranhão: Fundação Rio Bacanga. 29-44 (in Portuguese).

Almeida, S.S. 1996. Structures and floristic in mangrove areas of Pará: Evidence of amazon stuary influence. Boletim do Museu Paraense Emílio Goeldi. Série Ciências da Terra: v. 1, p. 93-100 (in Portuguese).

Amaral, D.D. et al. 2007. Fields and forests of river basins Atuá and Anajás, Marajo island, Pará. Belém: Museu Paraense Emílio Goeldi. Coleção Adolpho Ducke. 110P (in Portuguese).

Ayres, M. et al. 2003. Bio Estat 2.0: Statistics and applications in medical and biological sciences areas: Editora Sociedade Civil Mamirauá/Brasília. Conselho Nacional de Desenvolvimento Científico e Tecnológico (in Portuguese)

Barros, M.A.; Barth, O.M.; Costa, K. M. R. 1999. Pollen systematic of woody plants of southern Brazil. XXXII: Anacardiaceae. Leandra, (14): 17-24 (in Portuguese).

Bastos, M.N.C; Senna, C.S.F; Costa Neto, S.V. 2003. Plant communities in coastl landscapes of the Pará state: the sandbanks of the Crispim and Algodoal. In: Gente e Ambiente. Organizado por Lurdes Gonçalves Furtado \& Helena Doris A. Barbosa Quaresma. Belém: Museu Paraense Emílio Goeldi. p. 239-258 (in Portuguese).

Bauermann, S.G.; Marques-Toigo, M.; Neves, P.C.P. 2002. Taphonomic aspects of the Quaternary palinology. Pesquisas: Botânica, 52: 223-239 (in Portuguese).

Behling, H. \& Costa, M. L. 1997. Studies on Holocene tropical vegetation, mangrove and coasts environments in the state of Maranhão, NE Brazil. Quaternary of South America and Antarctic Peninsula 10 (7), 93-118.

Behling, H. \& Costa, M.L. 2001. Holocene vegetational and coastal environmental changes from the Lago Crispim record in northeastern Pará state, eastern Amazonia. Review of Paleobotany and Palynology. 114, 145-155.

Behling, H., Cohen, M. C. L. \& Lara, R. J. 2001. Studies on Holocene mangrove ecosystem dynamics of the Bragança Peninsula in northeastern Pará, Brazil. Palaeogeography, Palaeoclimatology, Palaeoecology, 40: 255-309.

Behling, H. 2001. Late quaternary environmental changes in the Lagoa da Curuça region (eastern Amazonia, Brazil) and evidence of Podocarpus in the Amazon lowland. Vegetation History and Archaeobotany. 10: 175 -183.

Behling, H., Cohen, M. C. L. \& Lara, R. J. 2004. Late Holocene mangrove dynamics of Marajó Island in Amazonia, northern Brazil. Vegetation History and Archaeobotany. Published online in 20 February 2004. 
Bove, C.P.; Barth, O.M. 1992. Systematic pollen Atlas of arboreal plants in southern Brazil. XXV: Bignoniaceae. Rev. Brasil. Biol., 52 (2): 283-292 (in Portuguese).

Carreira, L.M.M.; Silva, M.F.; Lopes, J.R.C.; Nascimento, L.A.S. 1996. Pollen of legums of the brasilian Amazon. Belém: Museu Paraense Emílio Goeldi. Coleção Adolpho Ducke. 137P (in Portuguese).

Carreira, L.M.M.; Barth, O.M. 2003. Pollen of plants of the Serra dos Carajás, Pará. Belém: Museu Paraense Emílio Goeldi. Coleção Adolpho Ducke. 112P (in Portuguese).

Carreira, L.M. M; Lobato, E.S.P.; Raposo, R.C. 1991a. Pollen morphology of plants of the Goeldi Museum Park. V. Família Malpighiaceae. Boletim do Museu Paraense Emílio Goeldi Botânica. 7 (2):441-453 (in Portuguese).

Carreira, L.M. M; Raposo, R.C.; Lobato, E.S.P. 1991b. Pollen morphology of cultivate plants at the Goeldi Museun Park. VI. Família Euphorbiaceae. Boletim do Museu Paraense Emilio Goeldi - Botânica. 7 (1): 157-175 (in Portuguese).

Cohen, MCL; Behling, H; Lara, R. J. 2005.Amazonian mangrove dynamics during the last millennium: The relative sea-level and the Little Ice Age. Review of Palaeobotany and Palynology. 136:93-108.

Colinvaux, P.A.; de Oliveira, P.E.; Patino, J.E.M. 1999. Amazon Pollen Manual and Atlas. Harwood Academic Publishers: Singapore. 330p.

Costa Neto, S.V; Bastos, M.N.C.; Lobato, L.C.B. 1996. Floristic composition and vegetation of the sandbank of Crispim, Marapanim municipality, Pará. Boletim do Museu Paraense Emílio Goeldi - Botânica. 12 (2): 237-249 (in Portuguese).

DHN. Diretoria de Hidrografia e Navegação (www.mar.mil.br/dhn/ dhn/index.html.) Acesso: em Julho de 2007.

Erdtman, G. 1952. Pollen morphology and plant taxonomy: Angiosperms. Stockholm, Almqvist \& Wiksell, 539p.

Erdtman, G. 1960. The acetolysis method in a revised description. Sv. Bot. Tidsk Lund, 54(4): 561-564.

Faegri, K. \& Iversen, J. 1950. Textbook of Modern Pollen Analysis. E. Munksgaard, Copenhagen, Denmark.

França, C.F. de. 2003. Morphology and coastal changes on the east bank of Marajo (PA). Tese de Doutorado (Doutorado em Geologia) Universidade Federal do Pará, Belém. 144P (in Portuguese).

França, C.F. de; Souza Filho, P.W.M. 2003. Analysis of morphological changes of coastal average period on the eastern of the Marajo island (PA) in landsat image. Revista Brasileira de Geociências, v. 33. $12 \mathrm{p}$ (in Portuguese).

Grimm, E.C. 1987. CONISS: A Fortran 77 program for stratigraphically constrained cluster analysis by the method of the incremental sumo f squares. Computer and Geosciences, 13: 13-35.

Hofmann, C. C. 2002. Pollen distribution in sub-Recent sedimentary environments of the Orinoco Delta (Venezuela) - an actuopalaeobotanical study. Review of Palaeobotany and Palynology. 119: 191-217.

IDESP. PARÁ.1974. Integrated studies of Marajo. Belém. 333P (in Portuguese).
Kapp, R.O. 2000. Pollen and spores. American Association of stratigraphic palynologists Foundation Publication.

Kisser, J. 1935. Bemerken for inclusion in glycerin gelatin. Z. Wiss. Mikr. 51p.(in German).

Laeyendecker-Roosenburg, D.M. 1966. A palynological investigation of archaeologically interesting sections in Northwestern Surinam. Leidse. Geol. Meded. Vol. 38: 31 - 36.

Lisboa, P.L.B.; Lisboa, R.C.L.; Rosa, N.A. \& Santos, M.R. 1993. Patterns of floristic diversity in the ecological reserve Bacurizal in Salvaterra, Marajo island, Pará. Boletim Museu Paraense Emílio Goeldi, Série Botânica, 9 (2): 223-248 (in Portuguese).

Mendes, A. C. 1994. Sedimentological and stratigraphic study of Holocene sediments from the coast Amapa, sector between Maraca island and Orange Cabo. Dissertação de Mestrado, Belém/Pará, Universidade Federal do Pará. 274 p (in Portuguese).

More, P.D. \& Webb, J.A. 1978. An Illustraded Guide to Pollen Analysis. Hodder and Stoughton. London. 133p.

Müller, I. 1947. Die pollen analttische nachweis der menschlichen Besiedlung im Federsee-und bodenseegebiet. Planta. 36P.

Müller, J. 1959. Palynology of Recent Orinoco delta and shelf sediments: Reports of the Orinoco shelf Expedition. Micropaleontology, 5 (1): 1-32.

Oliveira, F.P.M; Carreira, L.M.M.; Jardim, M.A. 1998. Characterization of pollen honey of Apis mellifera L. In secondary forest in the Igarapé - Açu/ Pará. Boletim do Museu Paraense Emílio Goeldi. Série Botânica. Belém. 14 (2): 159-176 (in Portuguese).

Roubik, D.W. \& Moreno, J.E.P. 1991. Pollen and Spores of Barro Colorado Island. Monographs in Systematic Botany from Missouri Botanical Garden, Panama. 270 p.

Rull, V.1987. A note on pollen counting in palaeoecology. Pollen et Spores, v. XXIX (4): 471-480.

Rull, V.; Vegas-Vilarrubia, T. \& Espinoza, N. P. 1999. Palynological record $\mathrm{f}$ an early-mid Holocene mangrove in eastern Venezuela: Implications for sea-level rise and disturbance history. Journal of Coastal Research, v. 15 (2): 496-504.

Rull, V.1998. Modern and Quaternary Palynological Studies in the Caribbean and Atlantic coasts of Northern South America: A paleoecologically-oriented review. Bol., Soc. Venezolana de Géol., 23 (2): 5-24.

Salgado-Labouriau, M. L. 1994. Ecological history of the Earth. São Paulo: Edgard Blücher. 307p.

Salgado-Labouriau, M. L.1973. Contribution to the palynology of the Cerrado. Rio de Janeiro, Academia Brasileira de Ciências. 291P (in Portuguese).

Salgado-Labouriau, M. L. \& Rull, V. 1986. A method of introduction exotic pollen for palaeoecological analysis of sediments. Review of Palaeobotany and Palynology, 47: 97-103.

Salgado-Labouriau. 2007. Standard and techniques for the Quaternary. São Paulo: Edgard Blüched. 440P (in Portuguese).

Santos, J.U.M. dos, Rosário, C.da S. 1988. Survey of vegetation used for dunes the Algodoal, PA. Boletim Museu Paraense Emílio Goeldi, Série Botânica, 4 (1): 133-151 (in Portuguese). 
São Thiago, L.E.U. 2005. Pollen analisys in mangrove area of environment protection (APA) of Guapamirim, Rio de Janeiro, Brazil. Dissertação de Mestrado (Mestrado em Ciências Geologia). Universidade Federal do Rio de Janeiro. 95P (in Portuguese).

Schaeffer-Novelli, Y. et al. 2000. Brazilian mangroves. Aquatic Ecosystem Health and Management. 3, p. 561-570.

Senna, C. S. F. 2002. Changes paleobotany and paleoenvironments Holocene coastal plain of the northeast ragion of the State of Para between the bays Marapanim and Maracanã. Tese de Doutorado apresentada à Universidade do Amazonas/ Instituto nacional de Pesquisas da Amazônia, Manaus-Amazonas, 115p. (in Portuguese)

Senna, C. S. F.; Oliveira, D. S. 2002. Composition, abundance and diversity of pollen types in paleoenvironments River stuary Marapanim, State of Pará. Prost, M.T. mendes A. (Org). In:
Ecossistemas Amazônicos: Dinâmicas, impactos e valorização de recursos naturais, UFPA/MPEG. 15P (in Portuguese).

Silvestre-Capelato, M.S. F; Melhen. T.S. 1997. Pollen flora of reserve state of Fontes do Ipiranga, São paulo, Brazil. Família: 81- Leguminosae. Hoehnea. 24(1): 115-163 (in Portuguese).

Tissot, C.; Marius, C. 1992. Holocene Evolution of the Mangrove Ecosystem in French Guiana: A Palynological Study. Tropical Ecosystems: Ecology and Management. 333 - 347.

Van der Hammen, T. 1963. A palynological study on the Quaternary of British Guiana. Leidse Geologishe Mededelingen, 29, 125-180.

Vedel, V.; Behling, H.; Cohen, M.; Lara, R. 2005. Holocene mangrove dynamics and sea-level changes in northern Brazil, inferences from the Taperebal core in northeastern Para State. Veget. Hist. Archaeobot. 15:115-123

Recebido em 22/07/2009

Aceito em 07/01/2010 
